\title{
British National Formulary: its birth, death, and rebirth
}

\author{
O L Wade
}

The British National Formulary is a direct descendant of the National War Formulary, in which the titles of the preparations were in Latin and the doses in minims and grains. The British National Formulary was born in 1948, did a good job for about 20 years, but sickened and died in 1976. It was reborn in 1981 . Parturition was painful with a very hostile reception from the media and the drug industry, but it survived and has grown in stature. The 25th edition was published in February. Wish it well for the next 25 issues!

The 25th issue of the current British National Formulary was published in February, and it seems a good moment to look back at my association with the formulary, which started 30 years ago in 1963.

\section{National War Formulary}

When war came in 1939 the minister for health appointed a small committee to prepare a formulary for wartime use. Its introduction stated that it contained "a selection of medicaments sufficient in range to meet the ordinary requirements of therapeutics." As I thumb through my ancient copy I realise how much medicine has changed in my professional life. There were 380 preparations; the titles were in Latin; the doses were in the apothecaries' system of minims and grains; and there was an inappropriately large assortment of tonics, cough mixtures, and aperients, such as Mistura Ammonii Chloridi et Morphini and Mistura Cascarae et Nucis Vomicae. There were three enemas, and it is difficult now to understand why Enema Fellis Bovini (bovine bile enema) was needed for the war effort. The formulary did, however, contain three important chemotherapeutic drugs: sulphonilamide, sulphathiazol, and sulphapyridine (used to treat Churchill when he contracted pneumonia while visiting troops in North Africa).

\section{Birth of the British National Formulary}

When the war ended it was the two non-governmental bodies that had been most closely associated with the National War Formulary, the Pharmaceutical Society of Great Britain and the British Medical Association, which wanted to continue publication of a formulary for general use. Thus the British National Formulary was born-a direct descendant of the war formulary.

The first edition was published in 1949 , and new editions appeared thereafter about every three years until 1976. When I was appointed a member of the Joint Formulary Committee in 1963, I did not know that I was to hold that appointment for 21 years.

It was an enormous committee with 38 members, doctors and pharmacists. Most of the doctors were general practitioners and a lot of the work for the medical members fell on a few of us who were in academic life. This included our chairman, Andrew Wilson from Liverpool, and Graham Wilson from Sheffield, Alastair Macgregor from Aberdeen, Roy Goulding from Guy's, and myself from Belfast; all of us were to become close friends.

Much of the time of the committee was spent in

deciding which drugs and preparations were to be selected for inclusion in the formulary. The general practitioner members were mostly elderly and very conservative in their views, and they tended to resent any changes in the formulary. There was much prolonged and detailed discussion, sometimes heated, about the notes for prescribers, which came at the beginning of the book and at the beginning of each section about different groups of drugs-alimentary, cardiovascular, anti-infective, etc.

The usual procedure was for a member of the committee, usually one of the academic members, to be asked to produce a draft of one of the sections, and this was then discussed and modified in committee. It was a slow and often tedious business. The meetings were held in a large and gloomy committee room at BMA House in Tavistock Square. They started at $10 \mathrm{am}$ and seldom finished before 4 or $5 \mathrm{pm}$. I often had difficulty in getting to Euston, only a few hundred yards away, in time to get the boat train to Liverpool at $4.55 \mathrm{pm}$ or to Heysham at $5.40 \mathrm{pm}$.

By the time I joined the committee English had already replaced Latin in the British National Formulary, and the old apothecaries' system of grains and minims was being replaced with what some members thought was the new fangled metric system. Monographs on new and important drugs such as the penicillins, tetracyclines, and corticosteroids had been included in the formulary, but there were still a lot of traditional tonics and mixtures. I remember very vividly dear old Dr Leak of Lee in Staffordshire, who always fought a strong rearguard action to prevent us deleting any of them. I admired Andrew Wilson; he was extremely tolerant and patient and very skilled at calming tempers, and I learnt a lot on how to handle difficult meetings by watching him.

Over the next 14 years I was asked at one time or another to put my hand to drafting almost every section of the formulary: drug dependence, prescribing for the elderly, adverse reactions to drugs, notes on drugs for the alimentary, cardiovascular, respiratory, and nervous systems and for infectious diseases and on vaccines. It was rather like undertaking a continuous comprehensive refresher course, and it helped me in my teaching both to undergraduates and to general practitioners as I felt confident that I was fully conversant with current thinking and practice.

The constitution of the Joint Formulary Committee was modified in 1969; it became smaller and a number of younger and well informed people were appointed. The new chairman was Dr John Bishop Harman. The meetings became shorter and more productive. By this time there was a flood of new drugs and preparations of drugs being introduced and marketed. It was our aim to include in the formulary an appropriate selection of these. There were some groups of drugs, such as the antihistamines and the hypnotics, for which scores of different drugs and preparations were available. We made what we thought was an appropriate selection. We admitted that our selection was arbitrary, and we tended to include those that were already most commonly used.

We had great difficulty with new drugs. Would they turn out as useful as the firms that marketed them claimed? Our policy was to include only those whose 
effectiveness was reasonably certain, but we knew that this was done at the expense of being out of fashion, and sometimes we were very late at including in the formulary really valuable new drugs.

\section{Death}

It became increasingly clear during the early 1970 s that the formulary was being less and less used by doctors. The pharmaceutial industry was publishing the Monthly Index of Medical Specialities every month. Compared with this the British National Formulary, which was produced every three years, was very soon out of date. The monthly index was on the desk of every practitioner and in the pocket of every house officer. It was estimated that $80 \%$ of prescribing by doctors was done with the index and only $20 \%$ with the formulary.

In 1975 the Medicines Commission, of which I was a member, was becoming concerned that the prescribing habits of doctors were being unduly influenced by the pharmaceutical industry, and it was suggested to the Department of Health and Social Security that a new and more comprehensive national formulary was needed that would (a) no longer be selective but give information about all medicines available in the country for prescribing by doctors; (b) give information about the price of medicines; $(c)$ be easy to use; $(d)$ be a handbook and fit into a coat pocket; and $(e)$ be kept up to date.

Discussion and negotiations between the Department of Health and Social Security, the BMA, and the Pharmaceutical Society started in 1975 and continued for the next three years. There was increasing concern at the delay in concluding negotiations because the 1976 edition of the British National Formulary was becoming more and more out of date. It was realised that the production of a new type of formulary would entail a great deal of work and that the new book would not be available for at least two and perhaps three years, by which time it might turn out to be unwanted because doctors had got used to obtaining information on drugs from other sources. However, in 1978 the Department of Health and Social Security gave an assurance to the two societies that if they would produce a new national formulary that met the specifications outlined above, it would purchase the book and distribute it to all doctors and pharmacists in the National Health Service. This important decision owed a great deal to Dr Ed Harris-at that time deputy

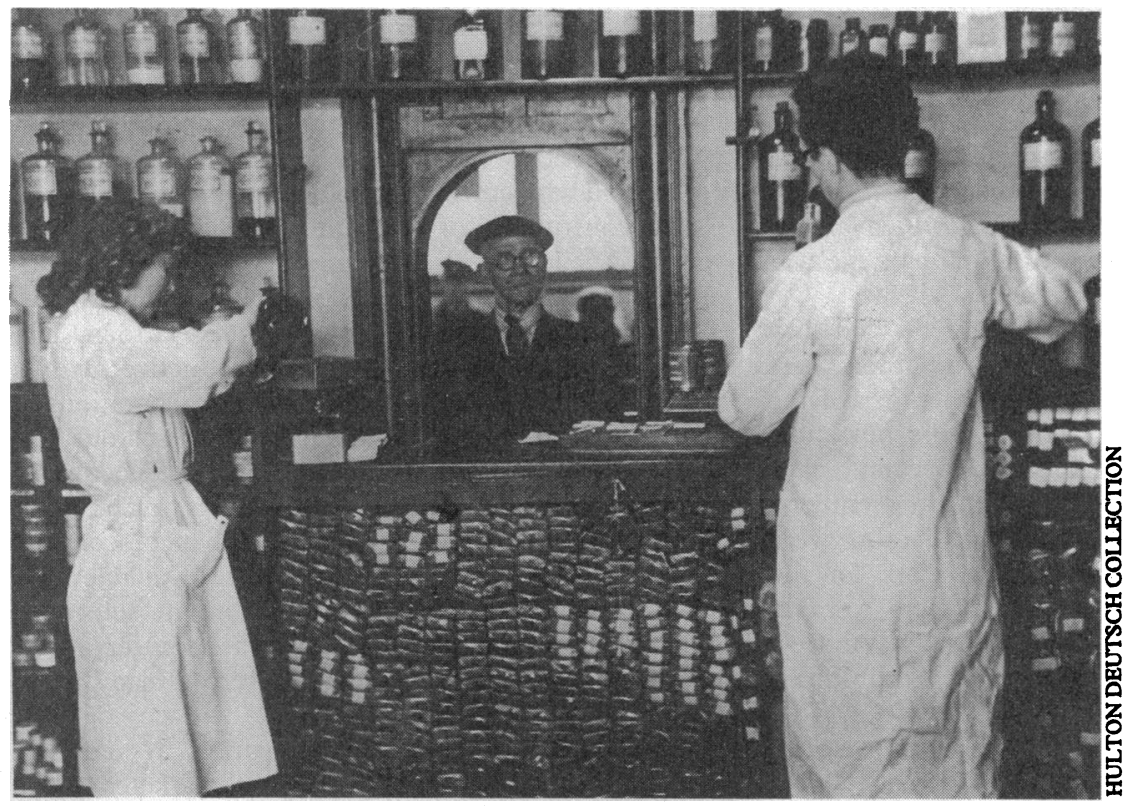

In the 1940s prescribing centred on tonics, cough mixcures; and aperients chief medical officer at the department. Few if any doctors and pharmacists know of the debt we owe to him; without that decision the British National Formulary would not have been reborn.

\section{Rebirth}

In December 1978 a new and smaller Joint Formulary Committee was appointed. I was asked to be the new chairman. There were two secretaries to the committee, one from the BMA and one -from the Pharmaceutical Society, and nine members, three from the BMA, three from the Pharmaceutical Society, and three from the Department of Health and Social Security (box).

\section{Joint Formulary Committee, 1978-81}

Chairman: O L Wade.

Deputy chairman: J P Kerr

From the British Medical Association: M Goodman, G M Mitchell, G R Tudhope

From the Pharmaceutical Society of Great Britain: J E Balmford, C R Hitchings

From the Department of Social Security: P R Greenfield, J P Griffin, B A Willis

Joint secretaries: J D J Havard (until Dec 1979), F O Wells (from Jan 1980) for the BMA; S C Jolly for the Pharmaceutical Society

Executive editor: $\mathrm{G}$ R Brown

General editor: A Wade

Editorial staff: K B K Davis, Sheenagh M Langtry, Jasmine Miller

Executive secretary: Rosemary L Weston

We met for the first time in Febuary 1979. We appointed Mr Ron Brown as the editor. That was a splendid appointment. He had worked on the production of the British Pharmacopoeia and Martindale: The Extra Pharmacopoeia for many years and brought a wealth of professional experience to the production of the new formulary. He was supported by Mr Ainley Wade (no relation, but nice to have another Wade around) and three staff pharmacists.

We had no doubt that the task ahead of us was a daunting one. The main part of the book was to contain monographs of every preparation that was on the market in the United Kingdom arranged in sections according to their use: gastrointestinal, cardiovascular, respiratory, etc. Each section was to be preceded by notes on the use of the drugs. For these notes we chose an author and two referees for each section. The author produced a draft which was commented on by the referees, and then the final decision on what was to be printed was made by the committee. It was a great help that my colleagues and I knew personally most of the people whom we asked to be authors and referees, and perhaps for that reason we never had any prima donna nonsense.

The preparation of the monographs was a much heavier task than the preparation of the notes for prescribers and presented us with great difficulties. There was always a great deal of information available for every preparation, but we were producing a handbook and we needed to confine the entry for each preparation to the information that doctors actually needed in order to make a decision when treating a patient.

In the sping of 1979 I prepared a draft of one section of the formulary, the cardiovascular section. I had help from Dr Linda Beeley, lecturer in my department at Birmingham, who had had unique experience in preparing drug information which could be called up 


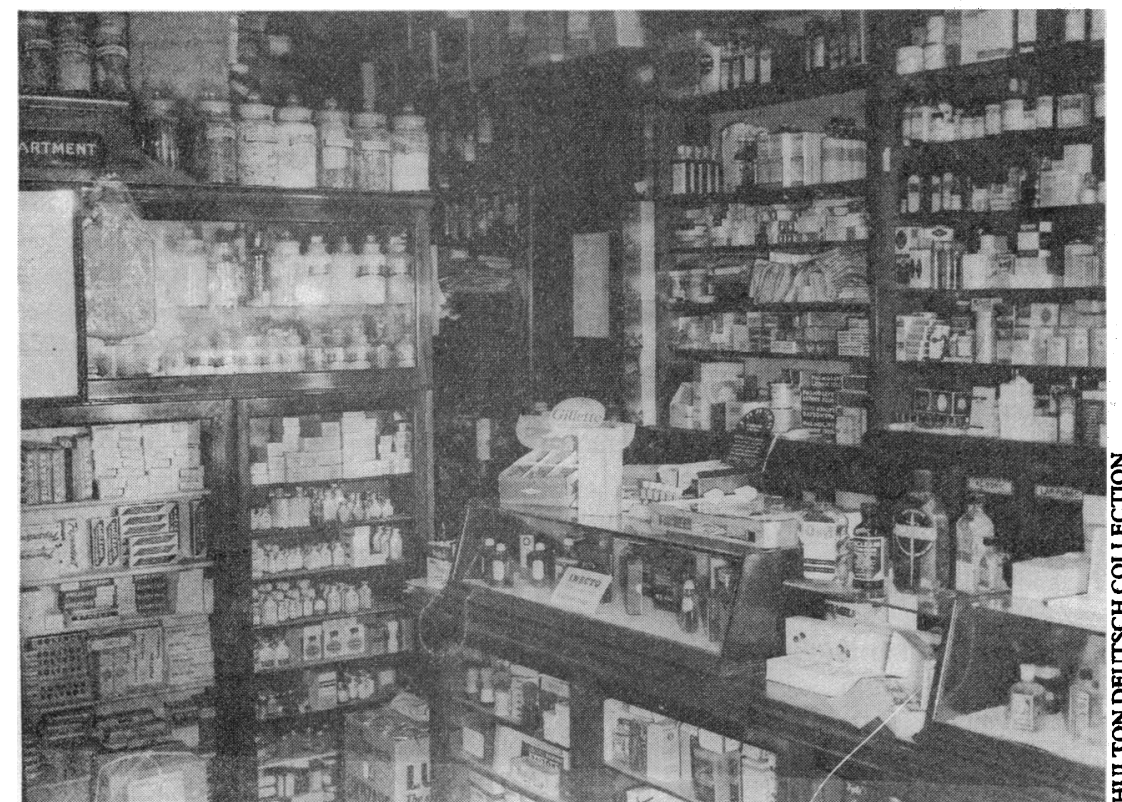

In the early 1950s more powerful drugs were starting to become available from pharmacies

on visual display units in the wards of the Queen Elizabeth Hospital. I also had the advantage that Dr Beeley, Sir Michael Drury, professor of general practice, Miss Patricia Alesbury, a young pharmacist, and I had recently produced a loose leaf book, Treatment,${ }^{1}$ which contained drug monographs similar to those I thought we needed for the formulary. It was a very tough job but I had two secretaries, Mrs Bourne and Mrs Stevenson, who took endless trouble to lay out the typescript in such a way that the monographs did not look crowded. We were all quite pleased with it.

This draft was examined by my colleagues on the committee and was modified slightly. Then the editor, $\mathrm{Mr}$ Brown, and his staff produced a mock up in print which showed that the information could be presented in a clear and accessible printed form. By October 1979 the committee had thus seen a definitive version of one section of the new British National Formulary, and it looked good. From then on, although it was hard work and an enormous amount of detail had to be checked and rechecked, it was straightforward and copy was ready for the printer by December 1980 . The print was set by computer so that modifications, additions, or deletions could be made with ease in subsequent editions. The first edition of the new British National Formulary, bound in ultramarine cloth, rolled off the press for publication and distribution throughout the NHS in February 1981. I received one of the first copies off the press, and every member of the committee signed its title page. It is now in the library of the Medical School at Birmingham.

\section{Reception}

The initial reception of the new British National Formulary from the media and the pharmaceutical industry was hostile and unpleasant. From the media this did not surprise me. Journalists who were familiar with commonly used proprietary cough mixtures and medicines used in their homes were amazed that most of them, if they appeared at all (proprietary medicines advertised to the public do not appear in the British National Formulary), appeared in small print, an indication of the opinion of the committee that they were of dubious value.

The Association of the British Pharmaceutical Industry and the staff of many of the pharmaceutical companies complained that the British National Formulary was inaccurate, inadequate, and unbalanced. This harsh criticism was because the formulary did not meet the requirements laid down by the Medicines Act for pharmaceutical companies when producing official data sheets about the medicines they intend to market. These requirements were aimed at ensuring that data sheets include extensive and completely comprehensive information about the product. The British National Formulary was not, however, marketing drugs and therefore did not have to meet the requirements of the Medicines Act. It is able to include in its monographs only such information as it believes is needed by doctors. It can list some products in small print, or express preferences. It is not bound to acquiesce to the idea that because a preparation has a licence it is necessarily desirable for widespread use.

The drug companies did not like, and possibly still dislike, the British National Formulary because in the notes for prescribers a group of preparations such as antidepressant drugs or thiazide diuretics are discussed together. This implies, of course, that there is little important difference between the various preparations and this is anathema to a company that spends a great deal of money trying to persuade doctors that its preparation is the best.

The reception of the new book by doctors and pharmacists was very different. They found it useful and were pleased with it. In hospitals it was soon seen in the pockets of all house officers and was well thumbed. General practitioners increasingly used it instead of the Monthly Index of Medical Specialities. Pharmacists found it an extremely convenient reference book. Even medical students spoke well of it and used it. It was appreciated and praised.

We published a new edition of the British National Formulary every six months. To many people this seemed an extravagant policy but experience has justified it. I am sure that if it had not been kept up to date and republished frequently the drug industry would have done its best to persuade doctors that it was not up to date and that they should use the monthly index instead of the British National Formulary. In each new edition there are 3000-4000 changes. Some of these may be very important: a new product is introduced or a preparation is taken off the market because a serious adverse reaction is reported, some new warning is needed, or some dose schedule is changed. Many changes are minor (at any rate to prescribers): a change in size or colour of tablets, a small change in formulation, or a change in the name of the manufacturing company or in the price of a preparation.

Every section of the notes for prescribers was revised over each period of two years, with changes in the authors and referees if appropriate. There were innovations. At the request of the Committee on Safety of Medicines yellow cards were included in the book so that doctors might more easily report their suspicions that a drug might be causing adverse reactions. With the help of the Royal Pharmaceutical Society guidance was included concerning the written instructions which were to be given to patients when their medicines were dispensed by their pharmacist. After a battle with the Department of Health and Social Security and much encouragement from my wife, who is a dentist, a version of the formulary was prepared every two years for dental surgeons and is much appreciated by them.

It was a problem to keep the British National Formulary as a handbook. There were always requests that information should be included which was more appropriate for a textbook than for a handbook. There were continued arguments about the best way to indicate the cost of drugs. The committee believed that doctors needed to be able to compare the price of preparations that are used for similar purposes, such as the many tranquillisers, analgesics, or diuretics that 
are available. For this purpose we gave the cost of 20 tablets of each preparation. But we had to admit that this might be misleading, for it is difficult to compare the cost of ordinary tablets of a drug with that of slow release tablets which, although much more expensive, only require one to be taken each day. Some people asked that we should give the cost of a week's treatment with the various preparations, although the problem of doing this is that the dosage for different patients would differ, and any average dosage which we might use in calculating the weekly cost would be rather arbitrary. We felt it was better to keep to the present system, the accuracy of which cannot be questioned.

\section{Conclusion}

This rebirth of the British National Formulary was a wonderful example of what a small team can achieve, and it showed how effectively doctors and pharmacists can work together. I like to think that we went a little way along the road to heal a breach between the two professions, which, in one way or another, has existed since 1518, when the physicians separated themselves from the apothecaries and Dr Linacre, physician to Henry VIII, founded the Royal College of Physicians.
The members of the Joint Formulary Committee met initially as professionals but, as we worked together, we developed deep mutual respect and close personal friendships. We all felt that we were superbly served by the editorial staff, led first by the late Ron Brown and then by Anne Prasad, both of them totally professional and dedicated to the formulary. We felt that we were doing something really useful for our professions and through them for patients, and we were happy in our work. Would that other committees were as worth while to sit on

I retired in 1984 after the 12 th edition. The 25 th edition may not have increased much in girth, but I think everyone will agree that it has grown in stature. I wish it well for its next 25 issues.

This article draws on a talk given to the Department of Clinical Pharmacology at the Universitat Autonoma de Barcelona. $^{2}$

1 Drury VWM, Wade OL, Beeley L, Alesbury P. Treatment. A handbook of drug therapy, London: Kluwer Medical, 1978.

2 Wade OL. El formulario Nacional Británico. Avances en Terapeutica 1992;16: 204-10

(Accepted 4 February 1993)

\section{Hammersmith Staff Rounds}

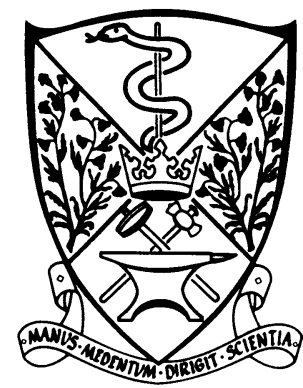

Royal Postgraduate

Medical School,

Hammersmith Hospital, London W12 0NN

Case presented by: S Levi, senior registrar in gastroenterology

C Foster, senior lecturer in histopathology

\section{Chairman:}

$\mathrm{H} \mathrm{J} F$ Hodgson, professor of gastroenterology

Discussion group: $\mathrm{KN}$ Ward, senior lecturer in virology

A So, senior lecturer in rheumatology

J A Garson, senior clinical lecturer in virology, University College London Medical School

J Waxman, reader in oncology D Swirsky, senior lecturer in haematology

Series edited by Dr Moira Whyte.

BMF 1993;306:1054-6

\section{Chronic liver disease due to hepatitis C}

\author{
Difficult to diagnose and treat
}

The low concentration of hepatitis $C$ virus in the blood of infected patients has made it difficult to detect. Infected patients can now be identified by using more sensitive immunoassays and amplification of viral RNA by the polymerase chain reaction. Nevertheless, the virus remains difficult to eliminate. We present the case of a woman with a history of autoimmune haemolytic anaemia, thrombocytopenia, and common variable immunodeficiency who developed chronic hepatitis.

\section{Case history}

A 36 year old woman was admitted to this hospital for investigation of abnormal liver function tests results in March 1991. In 1979 she had felt tired and unwell and was found to have a haemoglobin concentration of $28 \mathrm{~g} / 1$ with a Coombs' positive autoimmune haemolytic anaemia. This was treated with steroids and a blood transfusion. She recovered well and has subsequently had negative results on the Coombs' test. In 1983, however, she developed idiopathic thrombocytopenic purpura, requiring platelet transfusions and a splenectomy. Later that year she developed recurrent chest infections, and investigations showed panhypogammaglobulinaemia due to common variable immunodeficiency. This was treated successfully with immunoglobulin injections, and later with monthly immunoglobulin infusions.

In 1986 the thrombocytopenia recurred and she was treated with platelet transfusions, steroids, and azathioprine. The following year she developed jaundice, pale stools, and dark urine in addition to a pancytopenia. Azathioprine was stopped, and she required further blood transfusions. The jaundice cleared in six weeks, but during 1987-91 she continued to experience malaise and anorexia, with fluctuating liver function abnormalities.
Examination showed mild jaundice, palmar erythema, and spider naevi but no hepatic encephalopathy. Chest examination showed symptoms consistent with mild bronchiectasis. Her liver was of normal size and not tender.

Investigations included a full blood count and coagulation screen, which gave normal results. She had a low total protein concentration $(51 \mathrm{~g} / \mathrm{l})$ but a normal albumin concentration $(38 \mathrm{~g} / \mathrm{l})$. She was panhypogammaglobulinaemic (IgG 4.6 (normal range 5-16), $\operatorname{IgA}<0.07(1.25-4.25), \operatorname{IgM} 0.08(0.5-1 \cdot 8) \mathrm{g} / 1)$. Her bilirubin concentration was $76 \mu \mathrm{mol}(<17)$, aspartate aminotransferase $209(<35) \mathrm{IU} /$, alkaline phosphatase $414(<125) \mathrm{IU} / \mathrm{l}$, and $\gamma$-glutamyl transferase $414(<30)$ IU/l.

Importantly, an autoantibody screen, including antibodies to smooth muscle and nuclear bodies, gave negative results. Her serum was tested and found negative for antibodies to hepatitis A IgM, hepatitis B surface antigen and core antibody, hepatitis $\mathrm{C}$ antibody (first generation test), infectious mononucleosis, and cytomegalovirus antibody. Ferritin and copper studies gave normal results and her thyroid function was normal.

A liver biopsy showed normal vascular relations, with some focal necrosis and compensatory hyerplasia. Portal tracts were infiltrated with large numbers of lymphocytes. Mild piecemeal necrosis was present. These features suggested chronic active hepatitis without cirrhosis (fig 1).

The differential diagnosis included autoimmune chronic active hepatitis as well as viral hepatitis. Autoimmune chronic active hepatitis would have been consistent with the patient's age, sex, and autoimmune history, and the negative autoantibody tests could have resulted from the hypogammaglobulinaemia. Likewise, viral hepatitis acquired from the multiple blood product transfusions she had received was also a reasonable diagnosis, and once again the low circulating 